IP Periodica Polytechnica Civil Engineering

60(3), pp. 387,395, 2016

DOI: $10.3311 /$ PPci.8679

Creative Commons Attribution (1)

RESEARCH ARTICLE

\section{Application of Interferometry Method for Dynamic Continuous Testing of Bridges}

Damian Beben

Received 15-10-2015, revised 29-12-2015, accepted 06-01-2016

\section{Abstract}

The paper presents the selected results of experimental tests under dynamic loads that were conducted on various bridges structures (road-tram bridge, railway culvert and single-arch footbridge). The dynamic loads were caused by the passages of various trains, trams, trucks and pedestrians. The displacements of the bridge structures were monitored using the interferometric radar, which is a precision microwave instrument suitable to the automatic non-contact registering of vibrations and displacements of various engineering structures. Based on the measured displacements, the vibration frequencies of the bridge structures were determined using the FDD (Frequency Domain Decomposition) method. The received results show that the footbridge has the highest dynamic sensitivity of all studied bridge structures. Two first natural frequencies of the structures were distinguished what approximately corresponded to the dominant frequencies received from the forced vibration tests. The maximum displacements equalled $0.65 \times 10^{-3} \mathrm{~m} ; 5.75 \times 10^{-3} \mathrm{~m}$ and $2.23 \times 10^{-3} \mathrm{~m}$ for railway culvert, road-tram bridge and footbridge, respectively. Based on the frequencies of bridges, the logarithmic damping decrements (LDDs) and damping ratios ( $\zeta)$ were estimated. The highest $L D D=0.55$ and $\zeta=8.72 \%$ were obtained for the culvert. Generally, vibration frequencies and displacements of the bridges are safe from the functional and design point of view. The interferometric radar can be used instead typical sensors and measurement methods to monitor various engineering structures. Conclusions drawn from the field tests can be helpful in the measurements using the microwave interferometry method.

\section{Keywords}

Interferometric radar $\cdot$ bridges $\cdot$ dynamics $\cdot$ field testing $\mathcal{E}$ monitoring $\cdot$ displacement

\section{Damian Beben}

Department of Geodesy and Geotechnics, Faculty of Civil Engineering and Architecture, Opole University of Technology, Katowicka 48, 45-061 Opole, Poland

e-mail: d.beben@po.opole.pl

\section{Introduction}

The experimental tests of bridges are conducted in order to confirm structural specifications, or to provide diagnostic surveys for planning maintenance and modernization. Typical experimental tests are usually carried out using accelerometers, strain, inductive and wireless sensors [1--3]. Most of these sensors require direct contact to the structure for installation. Therefore, testing of structures can give rise to accessibility problems, often requiring use of the scaffolds. The satellite (GPS, GNSS, GLONASS), laser scanning (terrestrial (TLS), airborne (ALS) and mobile (MLS)) and classical geodesy (trigonometric and tachometric) methods are also used to measurements of various engineering structures [4,5]. However, the accuracy of these methods is unsatisfactory for civil engineering structures, especially bridges. For these reasons, the application of microwave interferometry method is a quite good alternative for continuous non-contact monitoring instead typical testing methods. Microwave interferometry method is a relatively new technology that can measure the static and dynamic displacements of various engineering structures as well as deformations of the land surface. Data are readily used to calculate the velocity, acceleration and resonant frequencies by the software. The interferometric radar named IBIS-S (Image By Interferometric Survey of Structures) was used in the tests.

Pieraccini et al. [6] and Gentile and Bernardini [7] give the comparison of the interferometric radar vs. the accelerometer used for dynamic monitoring of various large bridges. The differences in the displacements of these bridges were in the order of one-tenth of millimetres. The interferometry method for noncontact dynamic and static measurements of the vibration of various engineering structures (bridges, towers, buildings, slopes, stay-cables) were described by Dei et al. [8], Gentile [9], Pieraccini et al. [10, 11], Wang and Lin [12].

The main aim of the paper is presenting the possibility of dynamic testing of bridges using a non-contact microwave interferometric radar. This paper presents three case studies of the interferometric radar application to the monitoring of various bridge structures, wherein the typical displacement sensors were difficult to install (except for second structure). Each tested struc- 
tures is exposed to other type of excitations (loads). Background of the microwave interferometry and the Frequency Domain Decomposition (FDD) methods is also presented in the paper. Displacements of the bridges were monitored during the dynamic tests (normal traffic loads) continuously for 24 hours. Vibration frequencies were obtained using the FDD method. Based on the frequencies of bridges, the logarithmic damping decrements and damping ratios were estimated and compared to the bridge standards. The first structure is a steel road-tram bridge which consists of three spans, the second structure (railway culvert) is composed of two thin shells made of a corrugated steel plate (CSP) sheets interacting with the engineering soil and third one is a single-arch footbridge. In the case of second structure (similar to small tunnel), the possibility of displacement measurements using an interferometric radar was checked. For this reason, a typical inductive sensor was also installed. This was done because the typical conditions for the radar measurements could not be fulfilled. A special microwave horns IBIS-H23 type were used as the interferometer antennas (transmitting and receiving).

\section{Background of radar technique}

The IBIS-S interferometric radar with a range of $1000 \mathrm{~m}$ is designed to measure and analyse fast-changing movements and vibrations of the various structures. The interferometric system performs the precision measurement of changes of the reflected signal phase in relation to the emitted signal. In typical measurement conditions, the radar has the following characteristics:

- range resolution of $0.50 \mathrm{~m}$,

- the displacement measurement accuracy of $0.01 \mathrm{~mm}$,

- the sampling rate up to $200 \mathrm{~Hz}$.

It should be noted that the tested object may be situated $10-$ $4000 \mathrm{~m}$ from the instrument. The pixel distinguishability is achieved when the change of distance is $0.50-0.75 \mathrm{~m}$ and azimuth is $4.5 \mathrm{mrad}$. The basis of the instrument is the working radar with the $\mathrm{K}_{u}$-band $(17.1-17.3 \mathrm{GHz}$, the wavelength of $17.2-17.4 \mathrm{~mm}$ ), which uses the synthetic aperture method (InSAR). The radar distinguishes the source of the reflected signals according to their distance from the instrument. It results from stepwise frequency change (the range of $17.1-17.3 \mathrm{GHz}$ is divided into 256 intervals with linearly increasing frequency). Then, this distance is divided into sectors (bins) with a length of $0.50 \mathrm{~m}$. The sources located in one sector are indistinguishable. Each of the continuously repeated sequences of 256 successive signals takes $0.005 \mathrm{~s}$. Therefore, it is possible to register the location of points with the dominant reflections in each sector with a frequency of $200 \mathrm{~Hz}$, and thereby to detect their vibrations with frequency of $100 \mathrm{~Hz}$.

The microwave interferometric radar consists of the following modules: (i) sensor module. This unit is a coherent radar generating, transmitting and receiving the electromagnetic signals to be processed in order to compute the displacement time-history of the structure. The sensor module includes two horn antennas for transmission and reception of electromagnetic waves, and is installed on a tripod equipped with rotating head; (ii) control PC provided with the software; and (iii) power supply unit.

The sensor module emits a series of electromagnetic waves for the entire measurement period, and processes phase information at regular time intervals (up to $5 \mathrm{~ms}$ ) to find any displacement occurring between one emission and the next. The interferometric technique provides a measurement of the line-of-sight displacements of all the reflectors on the structure illuminated by the antenna beam simultaneously that are more than $0.50 \mathrm{~m}$. Once the line-of-sight or radial displacement $d_{r}$ has been evaluated, the vertical displacement $d$ can be easily calculated by employing a geometric projection (see Fig. 1).

The equipment is based on the Stepped Frequency - Continuous Wave (SF-CW) technique, that transmits, continuous waves at discrete frequency values, sampling a bandwidth $B$ at a constant interval $\Delta f[11]$. Pulse radars use short time duration pulses to obtain high range resolution. For a pulse radar, the range resolution $\Delta r$ is related to the pulse duration $\tau$ by the following Eq. (1):

$$
\Delta r=\frac{c \tau}{2},
$$

where $c$ is the speed of light in free space.

Since $\tau=1 / B$, the range resolution (1) may be expressed as Eq. (2):

$$
\Delta r=\frac{c}{2 B} \text {. }
$$

Radar has a narrow instantaneous bandwidth (corresponding to individual pulse) and attains a large effective bandwidth according to Eq. (3] [13]:

$$
B=(N-1) \Delta f
$$

The $N$ monochromatic waves are transmitted consecutively, each of them with a time duration of $\Delta t$ thus the sampling time $T$ of the field of view is given in form $T=N \Delta t[14]$.

The number $N$ of tones composing each burst can be calculated using Eq. (4):

$$
N=\frac{R_{\max }}{\Delta r}+1
$$

where $R_{\text {max }}$ is the maximum distance of measurements.

The concept of radar range resolution is presented in Fig. 2 . where an idealization of range profile is shown, as obtained when the radar transmitting beam illuminates a series of targets at various distances and various angles from the axis of the interferometric radar. The peaks presented in Fig. 2 correspond to measurement points that have good electromagnetic reflectivity. Fig. 2 also shows that the radar has 1-D imaging capabilities i.e. different targets can by individually detected if they are placed at different distances from the radar. Hence, the measurement errors may arise from the multiplicity of contributions to the 


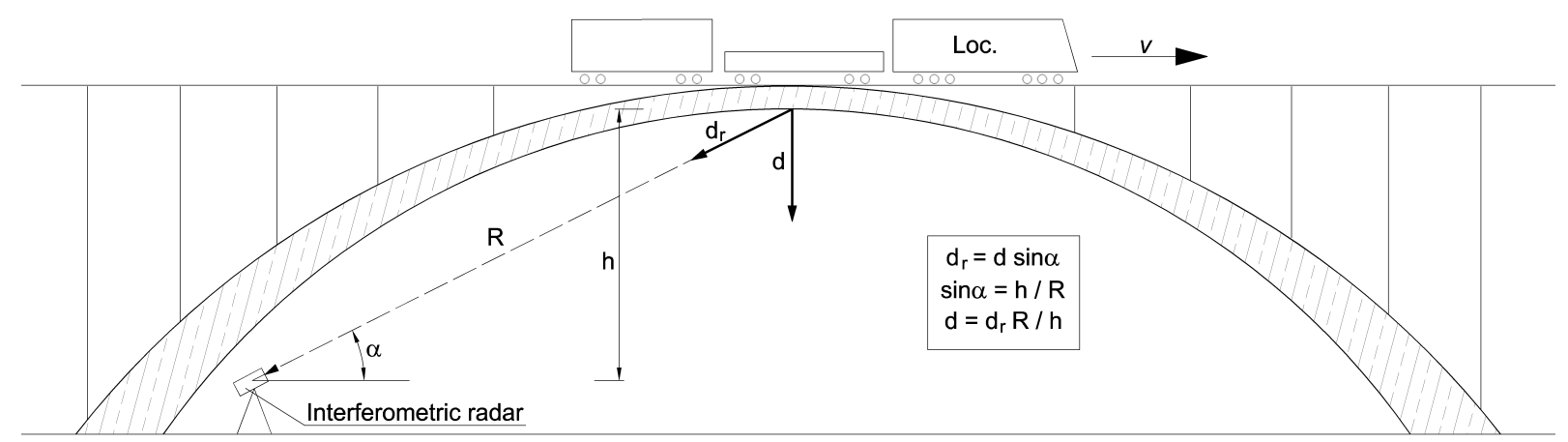

Fig. 1. Radial displacements versus projected vertical displacements

same range bin, coming from different points placed at the same distance from the radar but not lying on the same axis [15].

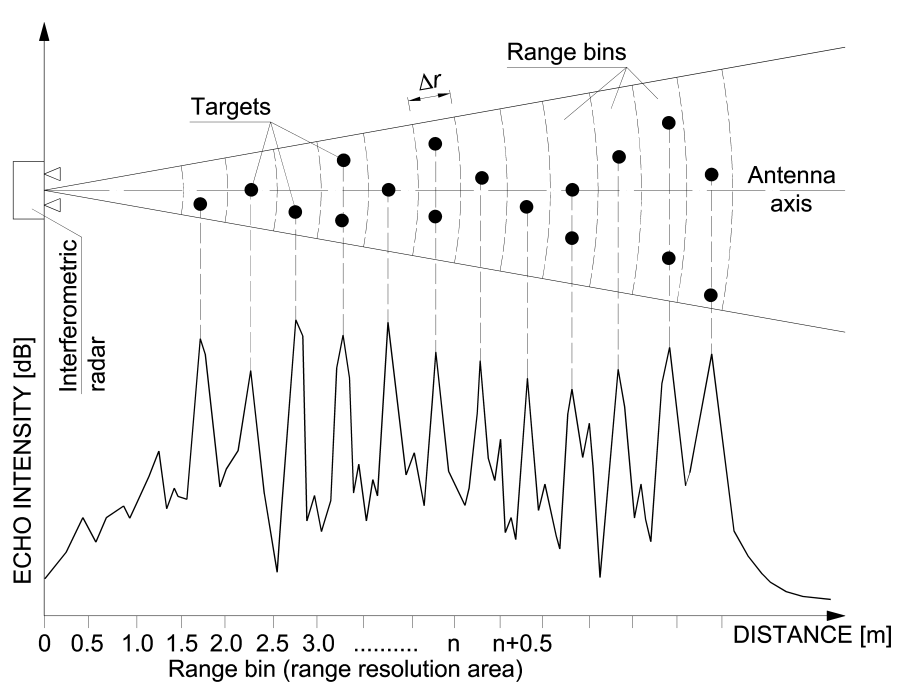

Fig. 2. Concept of a radar range resolution (range profile)

Caution must be paid about possible range measurement ambiguity due to the SF-CW radar. As the signal bandwidth $B$ is sampled at frequency step interval $\Delta f$, the principle of sampling states that unambiguous measurements can be made only if all detectable targets are closer than a maximum range given by Eq. (5):

$$
R_{\max }=\frac{c}{2 \Delta f} .
$$

In the SF-CW radar, the signal source locates at each frequency $f_{k}=f_{o}+k \Delta f(k=0,1,2, \ldots, N-1)$ long enough to allows the received echoes to reach the receiver [13]. So, the duration of each single pulse $T_{\text {tone }}$ depends on the maximum distance $R_{\max }$ and can be expressed as Eq. (6):

$$
T_{\text {tone }}=\frac{2 R_{\max }}{c} .
$$

Based on Eqs. (4) and (6), the maximum frequency sampling $f_{s}$ can be specified as Eq. (7):

$$
f_{s}=\frac{1}{N T_{\text {tone }}}=\frac{c}{2 N R_{\max }} \approx \frac{c \Delta R}{2 R_{\max }^{2}} .
$$

As the equipment is coherent interferometric radar, phase information is preserved. So, considering a single target, a dis- placement $d$ along the radar line-of-sight is detected by the related phase shift $\Delta \alpha$ impressed to the reflected signal according to Eq. (8):

$$
d=\frac{c}{4 \pi f_{c}} \Delta \alpha,
$$

where $f_{c}$ is the band center frequency.

\section{Descriptions of tested bridge structures and instru- mentations}

The first monitored object is the three-span road-tram bridge (named the Marshal Jozef Pilsudski Bridge (Fig. 3) which is located on the Vistula River in Cracow (Poland). The bridge connects the Kazimierz district with the Podgorze district. It was built in 1933 and during the World War II was blown up by the German troops. In 1948, the bridge was reopened to traffic. The bridge has $147.5 \mathrm{~m}$ long and $18.50 \mathrm{~m}$ wide. It weighs about 1200 tons. The main bridge span (middle) has $72 \mathrm{~m}$. It has a truss steel structure, and connections of individual components are riveted. The load bearing structure is supported on two pillars. The middle span of the bridge has a static scheme of the two-hinged arch. On the bridge, the one traffic lane in each direction is designed. These lanes are separated by the tram track and on the both sides there are the sidewalks for pedestrians.

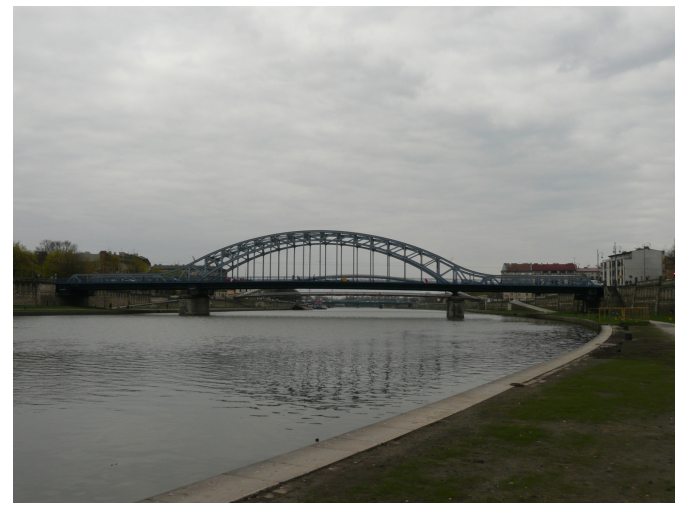

Fig. 3. Side view on the Marshal Jozef Pilsudski Bridge in Cracow

The experimental tests were carried out after sixty-three years of service of this bridge. The bridge displacements were registered during normal traffic continuously for 24 hours. 6252 vehicles were noticed (612 trams and 5631 cars). The measurement site with the radar was situated on the south bank of the Vistula 
river. In order to unambiguous identification of the reflected microwave beams on the bridge, the microwave reflectors horns were installed. The metallic reflectors were placed in the characteristic points of the bridge structure, i.e. over two pillars, in $1 / 4$ and in $1 / 2$ of the length of the middle span (the longest) as well as in the middle of the external spans. The maximum distance from the radar to the microwave reflector was about $60 \mathrm{~m}$. A special antenna horns IBIS-H23 with the widest beam (their obtuse angle for gain of $-3 \mathrm{~dB}$ is 38 degrees) for transmitting and receiving the microwaves were used [16].

The second example of dynamic testing using the interferometric radar is a corrugated steel plate (CSP) railway culvert (Fig.4). This culvert is located in Krosnowice, Poland. The corrugation depth of $0.05 \mathrm{~m}$, pitch of $0.15 \mathrm{~m}$ and steel sheet thickness of $0.003 \mathrm{~m}$ were used. The tested object is situated under the railway lines and consists of two shells in shape of closed arch. The effective length of shells is $4.40 \mathrm{~m}$ that are placed directly on a special profiled layer of soil substructure. The soil cover over the CSP culverts (including ballast, blanket and backfill) equals $2.40 \mathrm{~m}$. The width of the culvert shell at the top is $16.00 \mathrm{~m}$, whereas at the bottom is $21.80 \mathrm{~m}$, what it can be considered as a small tunnel. The height of culverts is $2.80 \mathrm{~m}$. In the plan view, the object is situated perpendicularly to the railway line. The monitoring were carried out after thirteen years of service of this culvert. The tests were conducted continuously for 24 hours. Forty-one trains were noticed (eighteen passenger trains; seventeen freight; six others).

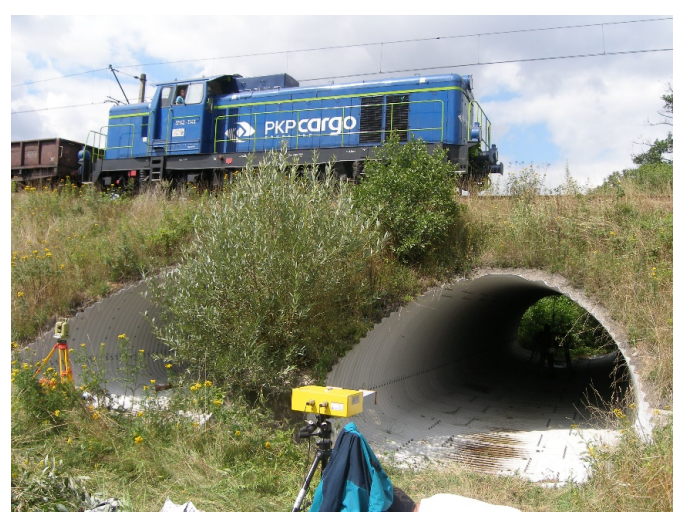

Fig. 4. Side view on CSP railway culvert in Krosnowice during tests

In these experimental studies, the distance from the radar to the microwave reflector was $14.5 \mathrm{~m}$ (bin=34). Typical conditions for the radar measurements [8,9] could not be fulfilled in the case of this culvert. First of all, the radar has possibility of measurements in the radial direction only. Thus, a special "transmission gear" was applied. Thanks to this mechanism, the vertical displacements of the culvert were transformed into the horizontal displacements. The mechanism operation is based on the assumption that "transmission gear" acts as a lever with one axis of rotation. The dynamic characteristics of "transmission gear" and the reflector were also determined. It was an extremely important problem, because it was necessary to distinguish the displacements spectra between the "transmission gear" and the CSP culvert. In the main test, frequencies varying from 9.5 to $10.0 \mathrm{~Hz}$ were considered as the natural vibration frequencies of the "transmission gear". As a result of preliminary control testing in the lab and field it was found that the "transmission gear" was operated in a satisfactory manner. Beben [17] describes the details of the „transmission gear" validation method. Secondly, the tested railway culvert is made from corrugated steel plates (pitch of $0.15 \mathrm{~m}$ ). Such a shape of the tested structure could result, potentially, in signal reflections (emitted by the interferometric radar) from the multi-surfaces. As a result of this phenomenon, the measurement signals reflected from the reflector might be drowned out. In order to reduce the risk of drowning out the signals, the measurement beam of microwaves was placed horizontally (close to the axis of the culvert). Moreover, special microwave horns of $\mathrm{H} 23$ type with a maximum gain of $23 \mathrm{dBi}$ were used as the interferometer antennas (transmitting and receiving). The measurement beam with the smallest obtuse angle is created: $-3 \mathrm{~dB}$ is $10^{\circ}$ vertically and $11^{\circ}$ horizontally, which corresponds to the width of the beam of $2.9 \mathrm{~m}$, on a distance of $16.5 \mathrm{~m}$ from the interferometer to the reflector. During the measurements, the signals reflected from the reflector were dominated significantly by the noise caused by other sources.

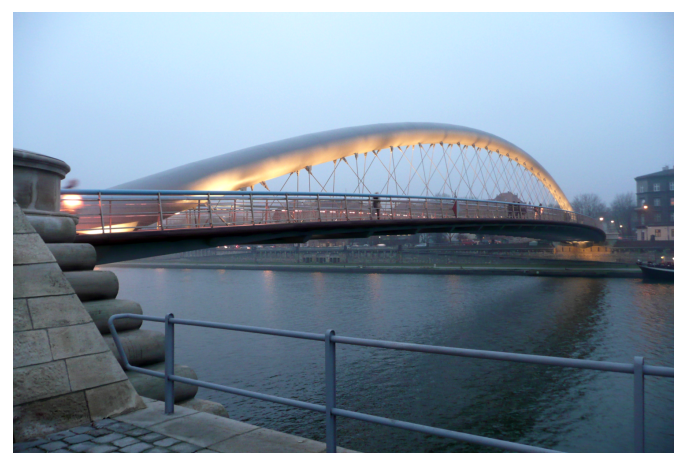

Fig. 5. Side view on the Father Bernatek footbridge in Cracow

The third monitored structure is a Father Bernatek footbridge situated in Cracow, Poland on the Vistula River (Fig. 5]. This footbridge connects the Kazimierz district with the Podgorze district. A footbridge has the main structure in the form of a steel single-arch spanned between the existing abutments of a Podgorski Bridge (previous old bridge). The footbridge has two decks, the first for the pedestrians and the second for the cyclists. The footbridge steel decks are suspended for this arch structure. The steel single-arch has a length of $145 \mathrm{~m}$, and both decks about $130 \mathrm{~m}$. The whole structure weighs more than 700 tons. The experimental tests were carried out after one year of service of this footbridge. The monitoring were conducted continuously for 24 hours during normal service. About 2000 pedestrians and 150 cyclists and were noticed. In order to unambiguous identification of the reflected microwave beams on the footbridge, the microwave metallic reflectors horns were installed. The reflectors were installed in characteristic points of the footbridge, i.e. in $1 / 2$ of the length of the span, where the maximum dis- 
placements were expected. In this case, the distance from the radar to the microwave reflector was about $100 \mathrm{~m}$. A special antenna horns IBIS-H23 were used (the same as in the case of the Marshal Jozef Pilsudski Bridge and the CSP culvert).

Generally in the monitored bridges, no signs of deformation, cracks, perforations, signs of flattening or spreading (in the case of CSP culvert) were observed. Joints defects were also not noted. The beginnings of the corrosion were only possible to observe (in the case of Marshal Jozef Pilsudski and CSP culvert). The overall rating of the bridge structures (Marshal Jozef Pilsudski and CSP culvert) according to the field inspection [18, 19] was "satisfactory", and in the case of Father Bernatek footbridge was "suitable".

\section{Test results, analysis and discussion}

In order to receive the frequencies of the monitored bridge structures, all datasets were performed using the Frequency Domain Decomposition (FDD) method. Brincker et al. [20] and Gentile and Bernardini [7] present detailed description of the FDD method. The main principle of the FDD method is revealed by realizing that any structural response $\mathbf{y}(t)$ can be described in the modal co-ordinates according to Eq. (9):

$$
\mathbf{y}(t)=\psi_{1} q_{1}(t)+\psi_{1} q_{2}(t)+\ldots+\boldsymbol{\psi}_{1} q_{n}(t)=\boldsymbol{\Psi} \boldsymbol{q}(t)
$$

where: $\boldsymbol{\psi}$ is a mode shape, $\mathbf{q}(t)$ is a modal coordinate and $\boldsymbol{\Psi}$ is a mode shape matrix.

The covariance matrix $\mathbf{C}_{y y}$ of the structure responses can be expressed by Eq. [10]:

$$
\mathbf{C}_{y y}(\tau)=E\left\{\mathbf{y}(t+\tau) \mathbf{y}(t)^{T}\right\}
$$

where: $E$ is the expectation value and the superscript ${ }^{T}$ denotes the complex conjugate matrix transpose.

By using Eq. (9), Eq. (11) is obtained:

$$
\mathbf{C}_{y y}(\tau)=E\left\{\boldsymbol{\psi q}(t+\tau) \mathbf{q}(t)^{T} \boldsymbol{\psi}^{T}\right\}=\boldsymbol{\psi} \mathbf{C}_{\mathrm{qq}}(\tau) \boldsymbol{\psi}^{T}
$$

where: $\mathbf{C}_{q q}(\tau)$ is a covariance matrix of the extended modal coordinates.

Using the Fourier transform, Eq. 12] is defined as:

$$
\mathbf{G}_{\mathrm{yy}}(f)=\boldsymbol{\psi} \mathbf{G}_{q q}(f) \boldsymbol{\psi}^{T}
$$

where: $\mathbf{G}_{y y}(f)$ is a spectral density matrix of the responses and $\mathbf{G}_{q q}(f)$ is a power spectral density matrix of the input.

Thus, if the modal coordinates are uncorrelated, the power spectral density matrix $\mathbf{G}_{q q}(f)$ of the modal coordinates is diagonal, and thus, if the mode shapes are orthogonal, then Eq. 12 presents a singular value decomposition (SVD) of the response spectral matrix.

Therefore, the FDD method is based on the SVD of the spectral density matrix, expressed as Eq. (13):

$$
\mathbf{G}_{y y}(f)=\mathbf{U}(f)\left[s_{i}\right] \mathbf{U}(f)^{T}
$$

where: $\left[s_{i}\right]$ is a diagonal matrix of singular values, $\mathbf{U}=\left[\mathbf{u}_{1}, \mathbf{u}_{2}, \ldots, \mathbf{u}_{n}\right]$ is a matrix of singular vectors.

Table 1 presents maximum displacements of analysed bridge structures. Using the FDD method, the dominant frequencies of these bridges were also determined. As can be seen in Table 11. maximum displacements of monitored bridge structures are strongly lower than their allowable deflections calculated based on bridge standards [21,22].

In the result of conducted experimental tests of the Marshal Jozef Pilsudski Bridge in Cracow, the displacements of selected points of the load carrying structure were obtained. The largest displacements of the bridge occurred in the middle of the longest span (central) and amounted to $\mathrm{d}_{\max }=5.75 \times 10^{-3} \mathrm{~m}$ (Fig. 6. a)) . Fig. 6 also shows three main peaks, which represent impact of axles of tram on the bridge. The first peak derive from two first tram axles, second peak (maximal displacement) come from the central two axles, and third one represents impact of two last axles. In other measurement points, the displacements do not exceed $2.0 \times 10^{-3} \mathrm{~m}$. The largest frequency of the bridge during tests does not exceed $2.0 \mathrm{~Hz}$ (Fig. 6.b)). Fig. 6p shows two dominant frequencies equalled $1.0 \mathrm{~Hz}$ and $1.8 \mathrm{~Hz}$, which can be emphasized as the first and second natural frequencies of the bridge, respectively. The maximum values of displacements and frequencies of the bridge were obtained during rides the trams (Bombardier NGT6 type). The total weight of passing tram was about $400 \mathrm{kN}$ (with passengers). The tram characteristics are: length $26 \mathrm{~m}$, width $2.4 \mathrm{~m}$, weight (without passengers) $300 \mathrm{kN}$, spacing of track $1.435 \mathrm{~m}$, maximal speed $70 \mathrm{~km} / \mathrm{h}(55 \mathrm{~km} / \mathrm{h}$ during tests), number of axles is 6 , axle spacing $1.8 \mathrm{~m}$. Traffic of the personal vehicles $(<3.5 \mathrm{Mg})$ did not result in the significant displacements of the bridge and it can be neglected in the bridge analysis.

Fig. 7 shows example of displacements of the CSP railway culvert crown using the interferometric radar and inductive sensor during passage of the freight train at the speed of $30 \mathrm{~km} / \mathrm{h}$. The effect of each axle of the freight train can actually be also observed from the displacement versus time plots. The total weight of passing train was $11.846 \mathrm{kN}$. During train rides, four main phases of displacements were emphasized. The first phase represents impact of locomotive and two heavy wagons. The maximum displacements amounted to $d_{\max }=0.53 \times 10^{-3} \mathrm{~m}$. The second phase relates to passage of four lighter wagons. In this stage the maximum displacements equalled almost $d=0.15 \times 10^{-3} \mathrm{~m}$. The third phase represents impact of eight heavy wagons. The largest displacements amounted to $d=0.22 \times 10^{-3} \mathrm{~m}$. In order to evaluate the possibility of the interferometric radar application, at the same time, the inductive sensor and geodesic measurements (trigonometric and tachometric methods) were used [17]. The inductive sensor and targets were placed in the same cross section of the CSP culvert in which the special "transmission gear" was fixed. So, three independent techniques for deflection measurements of the CSP culvert were applied, and the similar displace- 

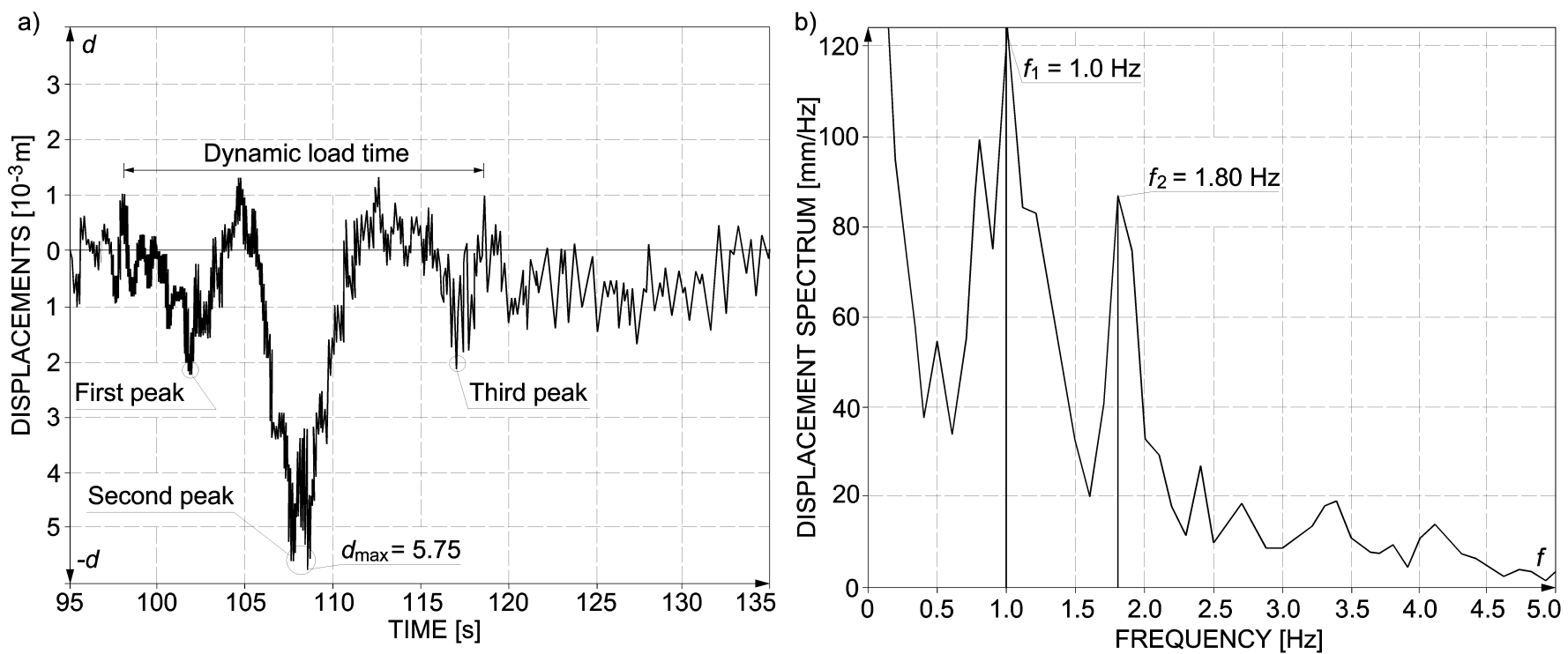

Fig. 6. Maximum displacements (a) and frequency (b) of the Marshal Josef Pilsudski Bridge during passage of the tram at the speed of $55 \mathrm{~km} / \mathrm{h}$

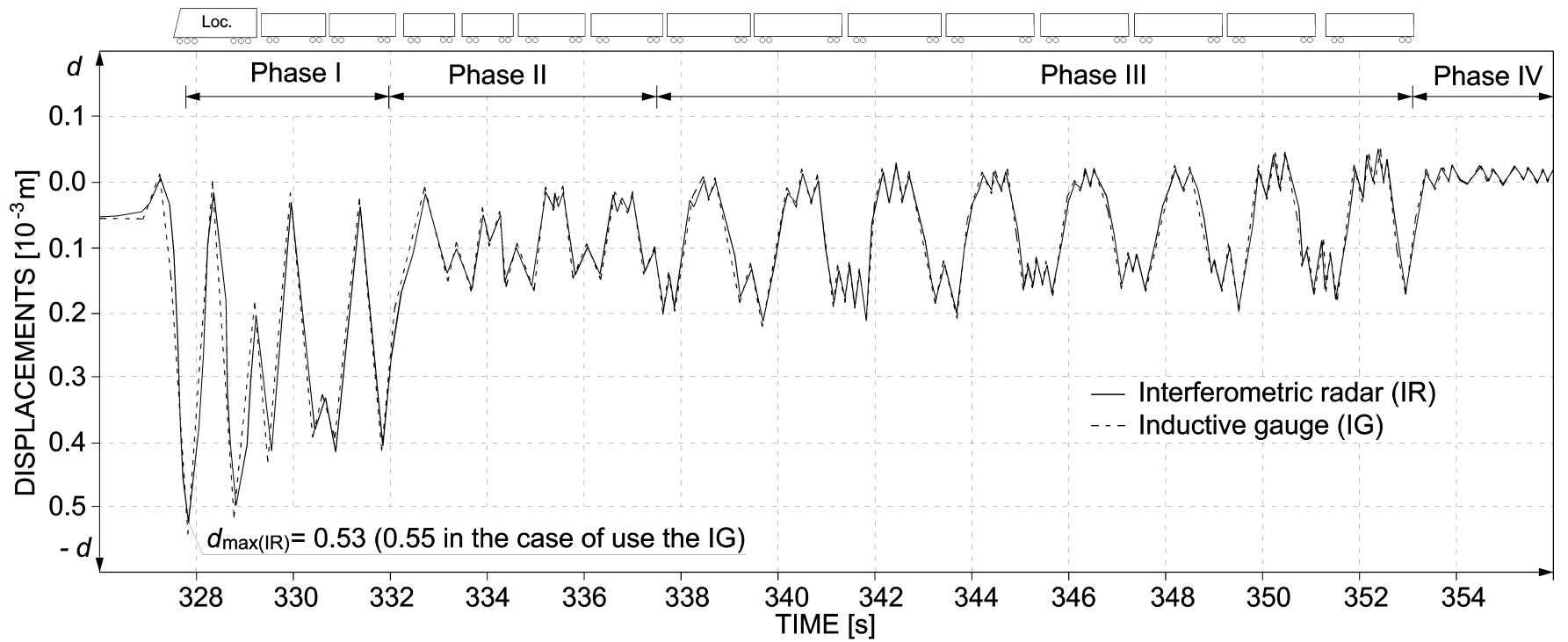

Fig. 7. Course of the CSP culvert displacements using the interferometric radar and inductive sensor during passage of the freight train at the speed of $30 \mathrm{~km} / \mathrm{h}$

ments were obtained. The highest frequencies during passing the freight train ranged from 0.8 to $2.5 \mathrm{~Hz}$ (see Fig. 8). The fourth phase relates to vibration reduction (damping) after passage of the freight train. This stage was dominated by frequency of $f=8.9 \mathrm{~Hz}$ which was identified, according to the preliminary tests, as a natural frequency of the "transmission gear". Taking into account the whole monitoring period (24 hours), the typical response of the CSP railway culvert to passing trains is usually the collection of three frequencies in the range of 0.6 to $3.0 \mathrm{~Hz}$. Three first natural frequencies of the culvert were $f_{1}=0.8 \mathrm{~Hz}, f_{2}=1.5 \mathrm{~Hz}$ and $f_{3}=2.5 \mathrm{~Hz}$, respectively; what approximately corresponds to the dominant frequencies received from the forced vibration tests. The highest frequencies were caused by passage of the express trains (speed was varying from 70 to $120 \mathrm{~km} / \mathrm{h}$ ). The maximum displacements of the culvert crown do not exceed $d_{\max }=0.65 \times 10^{-3} \mathrm{~m}$. They were obtained during passage of the heavy freight trains.

In the case of the footbridge, the maximum displacements

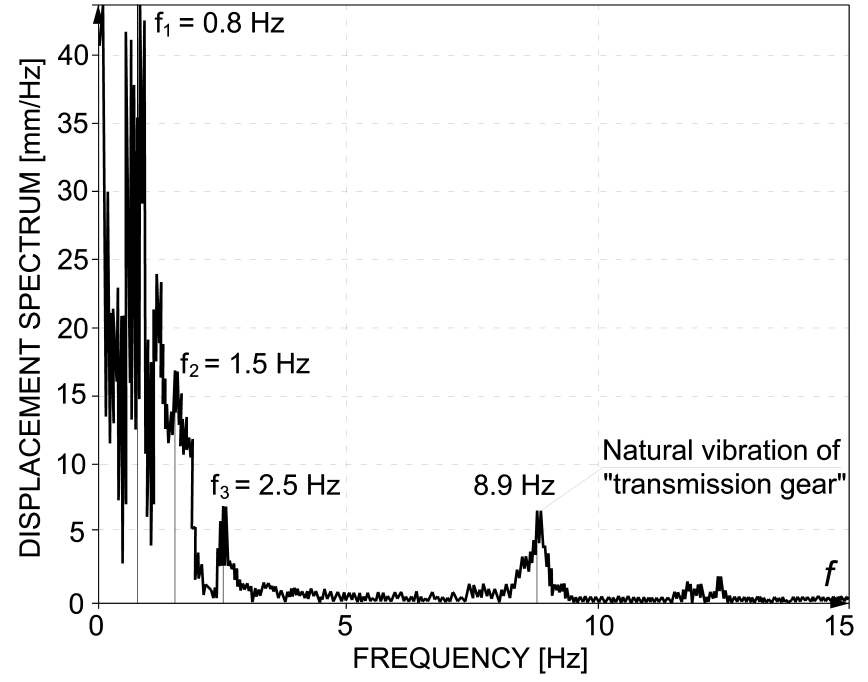

Fig. 8. Displacement spectra of the CSP culvert 
Tab. 1. Maximum displacements and frequencies of monitored bridge structures

\begin{tabular}{|c|c|c|c|}
\hline \multirow{2}{*}{ Bridge name } & \multicolumn{2}{|c|}{ Maximum value of: } & \multirow{2}{*}{ Allowable deflection $\left(10^{-3} \mathrm{~m}\right)$} \\
\hline & displacement $\left(10^{-3} \mathrm{~m}\right)$ & frequency $(\mathrm{Hz})$ & \\
\hline Marshal Josef Pilsudski & 5.75 & 1.0 and 1.8 & $l / 700=10321$ \\
\hline CSP culvert & 0.65 & $0.6-3.0$ & 8 22. \\
\hline Father Bernatek footbridge & 2.23 & 2.1 and 4.3 & $l / 300=48321$ \\
\hline
\end{tabular}

a)

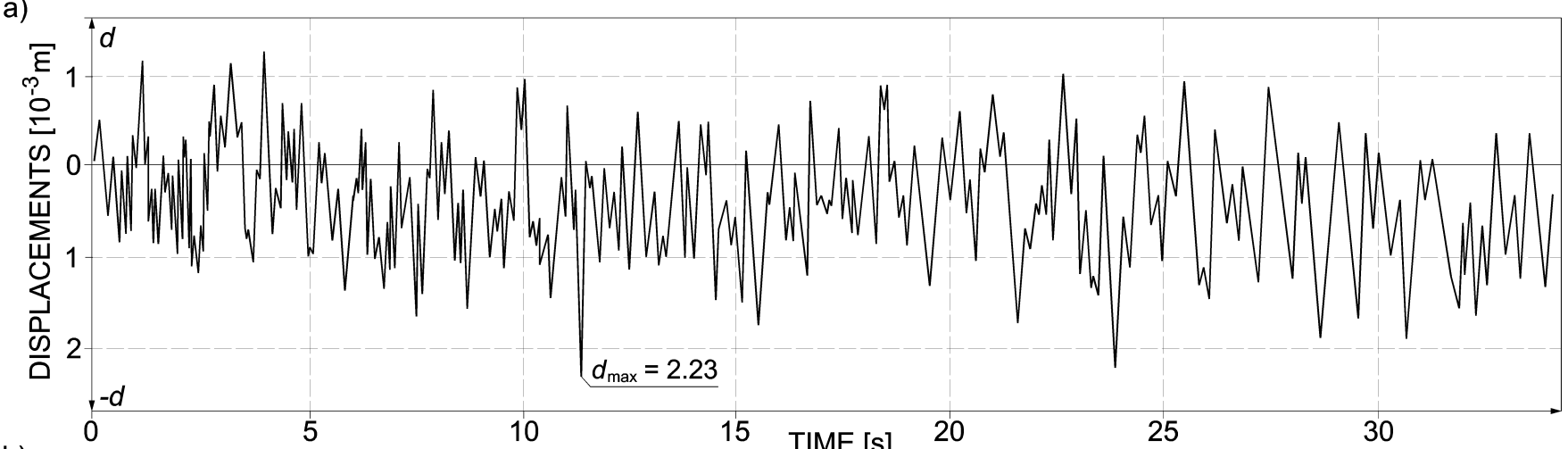

b)

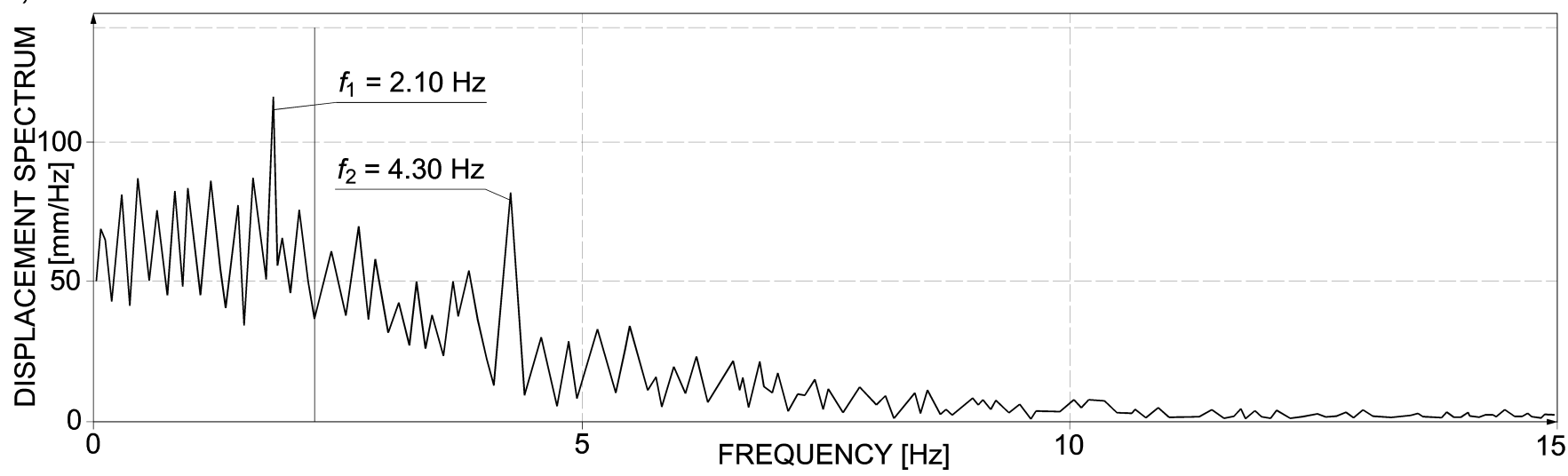

Fig. 9. Displacements course (a) and displacement spectrum (b) of the Father Bernatek footbridge during normal service loads

did not exceed $d_{\max }=2.23 \times 10^{-3} \mathrm{~m}$ (Fig. 9(a)). Fig. 9 a) also shows the selected displacement course versus time plots (almost $35 \mathrm{~s}$ ). Response the footbridge to the subjected loads is approximately the same in the whole testing period. Two characteristics displacement peaks (over $2.0 \times 10^{-3} \mathrm{~m}$ ) in Fig. 9 (a) can be observed. They were caused by passing the pedestrian groups (6- 8 individuals). The largest main frequency of the footbridge did not exceed $4.3 \mathrm{~Hz}$ (Fig. 9 b)). The less distinct frequency of the footbridge about $2.5 \mathrm{~Hz}$ can be also noted. Two first natural frequencies of the footbridge $f_{1}=2.1 \mathrm{~Hz}$ and $f_{2}=4.3 \mathrm{~Hz}$ were distinguished what approximately corresponds to the dominant frequencies received from the forced vibration tests. Received results of monitoring of the footbridge confirm a typical behaviour of such structures. Taking into account the whole testing period, passing the single individuals or moving cyclists through the footbridge did not cause larger displacements and frequencies.

Structural damping has important effects on the dynamic behavior of bridges because it is one of the main factors limiting the amplitude of vibrations. Damping of structures is mostly de- termined by the logarithmic damping decrement (LDD), which can be estimated in approximately, using Eq. (14):

$$
L D D=\frac{1}{r} \sum_{i=1}^{r} \ln \frac{d_{i}}{d_{i+1}},
$$

where $d_{i}$ is $i$-th particular amplitude of deflection; $d_{i+1}$ is $(i+1)$ amplitude of deflection; $r$ is number of addends.

The damping of structures may be estimated by the damping ratios that can be computed using Eq. (15):

$$
\zeta=\frac{1}{\sqrt{1+\left(\frac{2 \pi}{L D D}\right)^{2}}} \times 100 \% .
$$

The LDDs for the tested bridges were 0.27, 0.55 and 0.24 for Marshal Josef Pilsudski Bridge, railway culvert and Father Bernatek footbridge, respectively. Heavier trucks cause the LDD to take smaller values and greater values are for the lighter vehicles. The LDD for the culvert is the highest in comparison with other tested bridges, where the LDDs do not exceed 0.3. A similar situation is found in the case of the damping ratios $(\zeta)$. The damping ratios were $4.7 \%, 8.72 \%$ and $3.82 \%$ for Mar- 
shal Josef Pilsudski Bridge, railway culvert and Father Bernatek footbridge, respectively. The obtained results of damping ratios have confirmation in the literature, where for typical bridges, damping ratios usually do not exceed $7 \%$ [23].

The reason for such a difference is probably the effect of the activation of the soil-structure interaction in the CSP culvert, the increased friction damping in the soil as well as the thickness of soil cover above the culvert. So, the LDDs and the damping ratios in the tested bridges seem to depend mainly on the structures materials'. The weights and speeds of trucks have less influence the level of LDDs and damping ratios.

Application of the interferometric radar to monitoring of the dynamic behaviour of various bridge structures allows to obtain displacements of load-carrying structures with acceptable accuracy $(0.01 \mathrm{~mm})$. The presented results show that various position of the radar $(60 \mathrm{~m}, 14.5 \mathrm{~m}$ and $100 \mathrm{~m})$ in relation to the bridge structures does not cause any significant problems in measurements; even in the case of CSP culvert (which is similar to tunnel) where the typical measurement conditions for the radar were not fulfilled.

\section{Conclusions}

Basing on practical experience gained from observations concerning the interferometric radar application for dynamic testing as well as behavior of the various bridge structures, the following general conclusions can be drawn:

1 The interferometric radar is a suitable measurement instrument for the long-term monitoring of small-to-medium bridges or culverts. The radar gives possibility of obtaining the displacements and frequencies of the bridge structures very fast and with a high accuracy level in comparison to traditional sensors (and methods). The interferometric radar registered even very small values of displacements of the bridge structures with an accuracy in the order of $0.01 \mathrm{~mm}$. The FDD method allows to obtain the frequency of the bridge structures with accuracy of $0.1 \mathrm{~Hz}$.

2 The received results clearly show that the footbridge has the highest dynamic sensitivity (the largest vibration frequency equalled $4.3 \mathrm{~Hz}$ ) of all studied bridge structures. Two first natural frequencies of the structures were distinguished what approximately corresponded to the dominant frequencies received from the forced vibration tests. The maximum displacements equalled $0.65 \times 10^{-3} \mathrm{~m} ; 2.23 \times 10^{-3} \mathrm{~m}$; and $5.75 \times 10^{-3} \mathrm{~m}$ for the railway culvert, the Father Bernatek footbridge and the Marshal Josef Pilsudski Bridge, respectively. Generally, the range of frequencies and displacements of the tested bridges is safe from the functional and design point of view.

3 The logarithmic damping decrements (LDDs) and the damping ratios $(\zeta)$ for the CSP culvert were the highest $(\mathrm{LDD}=0.55, \zeta=8.72 \%)$ in comparison with other tested bridges in which do not exceed LDD $=0.3$ and $\zeta=5.0 \%$. This probably results from the ample thickness of soil cover over the culvert (which in this case damps vibrations) as well as effect of the activation of the soil-structure interaction.

4 The interferometric radar is a non-contact measuring device that can be used with confidence instead of the conventional sensors (for example inductive and dial sensors, accelerometers) which require to use the scaffolds or other additional equipment. In the case of the CSP railway culvert, three various measurement techniques were applied and very similar displacements were obtained. This proves that the application of the special constructed "transmission gear" did not influence measurement results significantly.

\section{References}

1 Lee JW, Kim JD, Yun CB, Yi JH, Shim JM, Health-monitoring method for bridges under ordinary traffic loading, Journal of Sound Vibration, 257(2), (2002), 247-264, DOI 10.1006/jsvi.2002.5056

2 Heieh KM, Halling HW, Barr PJ, Overview of vibrational structural health monitoring with representative case studies, Journal of Bridge Engineering, 11(6), (2006), 707-715, DOI 10.1061/(ASCE)1084-0702(2006)11:6(707)

3 Cunha A, Caetano E, Magalhaes F, Moutinho C, Recent perspectives in dynamic testing and monitoring of bridges, Structural Control Health Monitoring, 20(6), (2013), 853-877, DOI $10.1002 /$ stc. 1516

4 aefer DF, Truong-Hong L, Carr H, Singh M, Crack detection limits in unit based masonry with terrestrial laser scanning, NDT\&E International, 62(3), (2014), 66-76, DOI 10.1016/j.ndteint.2013.11.001

5 Larsen EK, Lattke F, Ott S, Winter S, Surveying and digital workflow in energy performance retrofit projects using prefabricated elements, Automation Construction, 20(8), (2011), 999-1011, DOI 10.1016/j.autcon.2011.04.001

6 Pieraccini M, Fratini M, Parrini F, Atzeni C, Partoli G, Interferometric radar vs. accelerometer for dynamic monitoring of large structures: An experimental comparison, NDT\&E International, 41(4), (2008), 258-264, DOI 10.1016/j.ndteint.2007.11.002

7 Gentile C, Bernardini G, Output-only modal identification of a reinforced concrete bridge from radar-based measurements, NDT\&E International, 41(7), (2008), 544-553, DOI 10.1016/j.ndteint.2008.04.005

8 Dei D, Pieraccini M, Fratini M, Atzeni C, Bartoli G, Detection of vertical bending and torsional movements of a bridge using a coherent radar, NDT\&E International, 42(8), (2009), 741-747, DOI 10.1016/j.ndteint.2009.07.001

9 Gentile C, Deflection measurement on vibrating stay cables by non-contact microwave interferometer, NDT\&E International, 43(3), (2010), 231-140, DOI $10.1016 /$ j.ndteint.2009.11.007

10 Pieraccini M, Luzi G, Mecatti D, Fratini M, Noferini L, Carissimi L, Franchioni G, Atzeni C, Remote sensing of building structural displacements using a microwave interferometer with imaging capability, NDT\&E International, 37(7), (2004), 545-550, DOI 10.1016/j.ndteint.2004.02.004

11 Pieraccini M, Parrini F, Dei D, Fratini M, Atzeni C, Dynamic characterization of bell-tower by interferometric sensor, NDT\&E International, 40(5), (2007), 390-396, DOI 10.1016/j.ndteint.2006.12.010

12 Wang K-L, Lin J-T, A basin scale assessment of landslide probability from differential interferometry of synthetic aperture radar, In: Furuta H, Frangopol DM, Akiyama M (eds.), Life-Cycle of Structural Systems: Design, Assessment, Maintenance and Management, Taylor\&Francis Group, 2015, pp. 1178-1183, DOI $10.1201 / \mathrm{b} 17618-203$

13 Bernardini G, Gentile C, Ricci P, New interferometric radar for full-scale testing of bridges: 1. radar techniques and static tests, In: Forde M (ed.), 
Proceedings of the 12th International Conference on Structural Faults and Repair, 2008, pp. 1-12.

14 Fratini M, Parrini F, Pieraccini M, Borri C, Atzeni C, Structural oscillation modes identification by applying controlled loads and using microwave interferometry, NDT\&E International, 42(8), (2009), 748-752, DOI 10.1016/j.ndteint.2009.07.002

15 Gentile C, Bernardini G, Ricci PP, Operational modal analysis of a cablestayed bridge from conventional and radar based-measurements, In: Brennan MJ (ed.), Proceedings of the 7th European Conference on Structural Dynamics, 2008, pp. 1-12.

16 Balut A, Measurements of engineering structures using the interferometric radar, In: Proceedings of the Scientific and Technical International Conference on Modern IDS Radar Equipment for Non-invasive Testing of Bridges, 2011.

17 Beben D, Application of the interferometric radar for dynamic tests of corrugated steel plate (CSP) culvert, NDT\&E International, 44(5), (2011), 405412, DOI 10.1016/j.ndteint.2011.04.001

18 Specifications for Railway Engineering Structures, The Polish Railway Lines; Warsaw, Poland, 2005. part IV.

19 Janas L, Michalak E, Rules for the Application of a Grading Scale of Technical Condition and Usability to Service of Road Engineering Structures, General Directorate for National Roads and Motorways; Warsaw, 2008.

20 Brincker R, Andersen P, Zhang L, Modal identification from ambient responses using frequency domain decomposition, In: Proceedings of the 18th International Modal Analysis Conference, 2000, pp. 625-630.

21 PN-82/S-10052. Bridge Structures. Steel Structures. Design, 1982. Polish Bridge Standards, Polish Committee of Standardization.

22 CEN, EN 1991-2. Eurocode 1: Actions on Structures, Part 2: Traffic Loads on Bridges, 2002. European Committee for Standardization.

23 Feng MQ, Lee SC, Determining the effective system damping of highway bridges, California Deptartment of Transportation; Sacramento, CA, 2009. Report CA-UCI-2009-001. 